\section{Medical Principles and Practice}

Med Princ Pract 2013;22:346-350

DOI: $10.1159 / 000346626$
Received: June 24, 2012

Accepted: December 16, 2012

Published online: February 5, 2013

\title{
Outcomes of Different Surgical Procedures in the Treatment of Spinal Tuberculosis in Adults
}

\author{
Xu Cui Yuan Zheng Ma Xing Chen Xiao Jun Cai Hong Wei Li Yi Bing Bai \\ Department of Orthopedics, 309th Hospital of PLA, Beijing, China
}

\section{Key Words}

Tuberculosis · Radical debridement · Kyphosis ·

Instrumentation

\begin{abstract}
Objective: To investigate surgical methods and outcomes in the treatment of spinal tuberculosis (TB) in adults. Subjects and Methods: One hundred and eighty-one patients (average age 39 years) without multiple-level noncontiguous spinal TB were followed up for 22-72 months. The patients were divided into four groups according to surgical procedure on the basis of the position and extension of the foci: group A (74 cases): anterior radical debridement and strut grafting with instrumentation; group B (83 cases): posterior instrumentation and bone grafting with anterior radical debridement and strut grafting in a single- or two-stage procedure; group C (10 cases): extrapleural anterolateral decompression and strut grafting with posterior instrumentation in thoracic or thoracolumbar spine, and group D (27 cases): single-stage transforaminal decompression and posterior instrumentation and fusion. Results: There was a significant decrease $(p<0.05)$ in mean preoperative $(81 \%)$ Oswestry's Disability Index. Except for 24 patients with lumbosacral TB who were only instrumented posteriorly, kyphosis degrees
\end{abstract}

\begin{tabular}{ll}
\hline KARGER & $\begin{array}{l}\text { ( } 2013 \text { S. Karger AG, Basel } \\
1011-7571 / 13 / 0224-0346 \$ 38.00 / 0 \quad \text { Karger }\end{array}$ \\
E-Mail karger@karger.com & $\begin{array}{l}\text { This is an Open Access article licensed under the terms of the } \\
\text { www.karger.com/mpp }\end{array}$ \\
& $\begin{array}{l}\text { Creative Commons Attribution-NonCommercial 3.0 Un- } \\
\text { ported license (CC BY-NC) (www.karger.com/OA-license), } \\
\text { applicable to the online version of the article only. Distribu- } \\
\text { tion permitted for non-commercial purposes only. }\end{array}$
\end{tabular}

were corrected by a mean of $11.5^{\circ}$ in the anterior instrumentation group and $12.6^{\circ}$ in the posterior instrumentation group $(p<0.01)$. The correction loss was $6.8^{\circ}$ in the anterior instrumentation group and $6.1^{\circ}$ in the posterior instrumentation group at the last follow-up $(p<0.01)$. Conclusion: The four surgical procedures obtained good results for correction and maintenance of the correction, clearance of the foci, decompression of the spinal cord and pain relief in the treatment of spinal TB in adults, providing that the operative indication is accurately identified. However, the posterior approach was superior to anterior instrumentation for correcting deformity and maintaining the correction.

Copyright $\odot 2013$ S. Karger AG, Basel

\section{Introduction}

The recent resurgence of tuberculosis (TB), an old disease, has been attributed to the human immunodeficiency virus epidemic, the emergence of multidrug resistance to TB and immigrants with a high prevalence of TB $[1,2]$. Skeletal system involvement occurs in $1-3 \%$ of patients, and up to $50 \%$ of those affected have TB of the spine [3, 4]. It is generally accepted that spinal TB is the most dangerous pattern of bone and joint TB because of its ability

Xu Cui, MD

Department of Orthopedics

309th Hospital of PLA

Beijing (China)

E-Mail cuixuprossor@163.com 
to cause bone destruction, deformity and paraplegia [5]. Antituberculous chemotherapy is the mainstay of spinal TB treatment. Yet patients treated conservatively have a mean increase in deformity of $15^{\circ}$, and for approximately $3-5 \%$, the final deformity is more than $60^{\circ}$ [2]. Radical debridement combined with fusion and instrumentation is utilized in patients with neurological deficit, caseous abscesses, sequestered bone formation, instability or a kyphotic angle of more than $30^{\circ}$ [6]. However, a controversy remains regarding the surgical approach and modality of instrumentation. The purpose of this study was to investigate the outcomes of different surgical procedures in the treatment of spinal TB in adults.

\section{Subjects and Methods}

Between January 2004 and December 2009, 241 adult patients with thoracic and lumbar spinal TB were treated with different surgical procedures. One hundred and eighty-one patients (average age 39 , range 16-67 years) without multiple-level noncontiguous spinal TB were followed up for 22-72 months. Out of 25 patients with neurological deficit, 11 were classified as Frankel type $\mathrm{C}$ and 14 as Frankel type D before surgery. The pathogenic vertebral levels included 4 contiguous thoracic vertebrae in 11, 3 contiguous vertebrae in 55, 2 contiguous vertebrae in 98, and the lesion localized at 1 vertebra in 17 cases. The kyphosis degrees ranged from -52 to $30^{\circ}$ in 104 cases, 31 to $60^{\circ}$ in 49 cases and 61 to $70^{\circ}$ in 28 cases. Erythrocyte sedimentation rates were elevated in 163 cases. A definitive diagnosis was made by pathological and/or microbiological examination of tissue removed at surgery. Two cases with pyogenic infection in the lumbar spine that could not be proved histologically were excluded from this study. Twentyfive patients underwent operation for neurological impairment with short-term chemotherapy regimen before surgery. The remaining 156 cases underwent more than 3 weeks of chemotherapy before surgery. Symptoms, kyphosis angle and functional and neurological status were the main parameters used for the clinical and radiological assessment. Clinical assessment was performed using the measured Oswestry Disability Index.

Patients were divided into four groups according to the surgical procedure on the basis of the position and extension of the foci. Group A: 74 cases lacking a large paraspinal abscess and without lumbosacral TB were subjected to anterior radical debridement and strut grafting with instrumentation (fig. 1a, 2b); group B: 83 cases with large paraspinal abscess, especially cases with lumbar $\mathrm{TB}$, were given the surgical treatment of posterior instrumentation with or without posterior column shortening along with simultaneous or staged anterior radical debridement plus titanium cage filled with morseled rib bone or large autoiliac or costal grafting [7] (fig. 2a, b); group C: 10 cases with thoracic or thoracolumbar spinal TB were given extrapleural anterolateral decompression and strut grafting with posterior instrumentation; group D: 27 cases with lumbar or lumbosacral TB underwent single-stage transforaminal decompression and posterior instrumentation and fusion [8].

Outcomes in the Surgical Treatment of Spinal TB in Adults
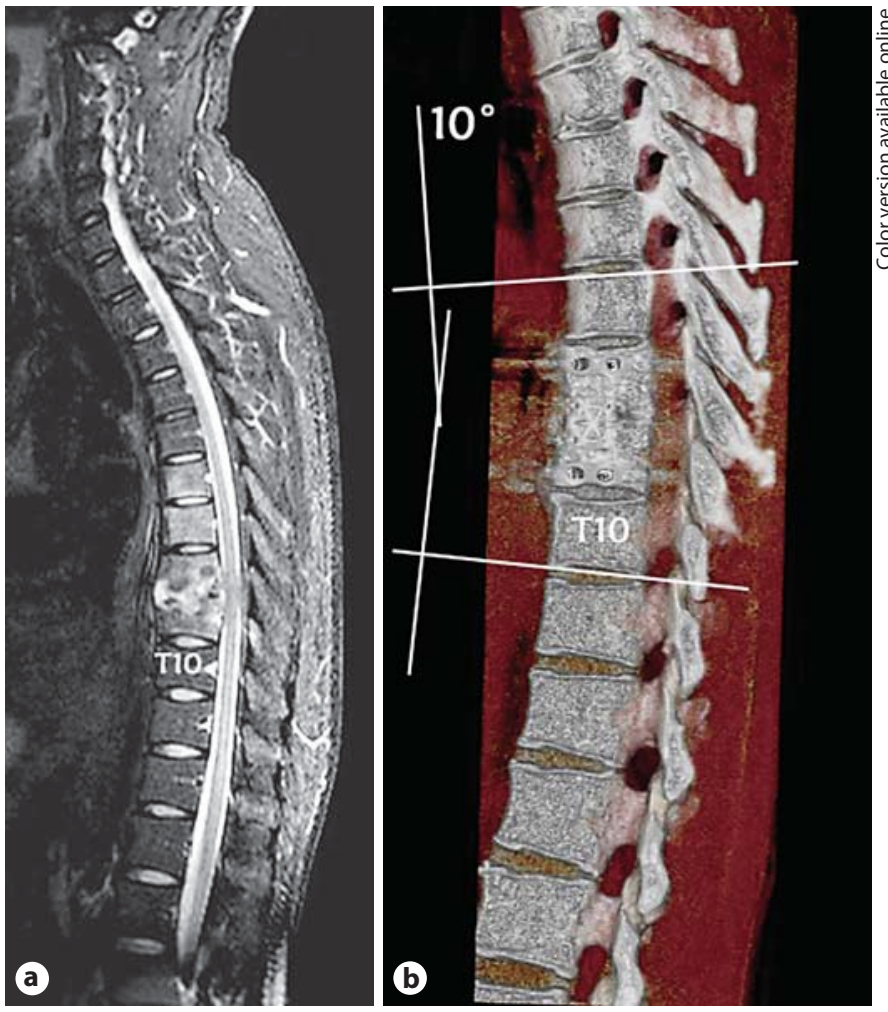

Fig. 1. a A 29-year-old man with spinal TB in the T8-9 vertebrae and sagittal magnetic resonance imaging showing destruction of the T6-9 vertebrae, especially the T8-9 vertebrae. b Fusion seen at 12 -month postoperative radiogram and a $4^{\circ}$ loss of correction seen in the local kyphosis angle.
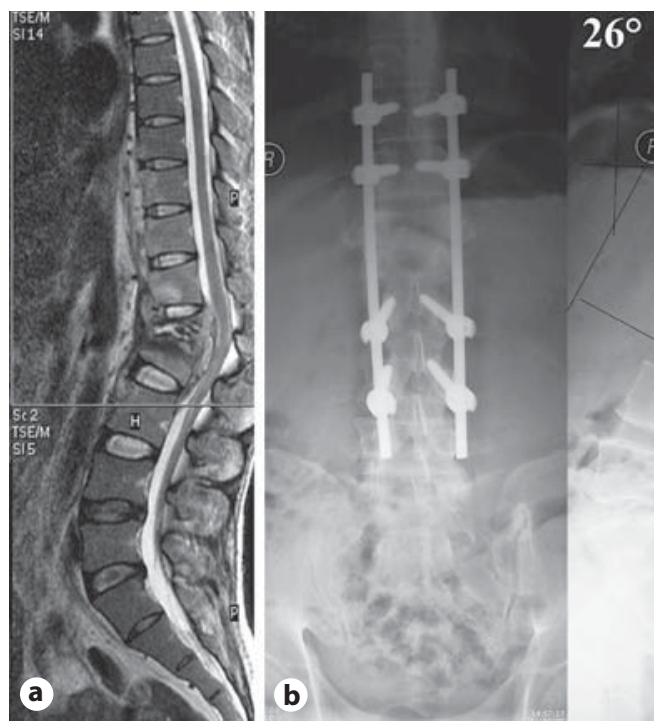

Fig. 2. a A 36-year-old man with spinal TB in the T11-L1 vertebrae and sagittal magnetic resonance imaging showing destruction of the T11-L1 vertebrae, especially the T12-L1 vertebrae. b There was a $8^{\circ}$ loss of correction in local kyphosis angle in the 13 -month postoperative radiogram. 
Table 1. Patient data

\begin{tabular}{llllll}
\hline Group & \multicolumn{2}{l}{ Distribution of pathologic vertebrae } & & Cases \\
\cline { 2 - 5 } & thoracic & thoracolumbar & lumbar & lumbosacral & \\
\hline A & 39 & 27 & 8 & 0 & 74 \\
B & 4 & 7 & 39 & 20 & 70 \\
C & 8 & 2 & 0 & 0 & 10 \\
D & 1 & 2 & 20 & 4 & 27 \\
\hline Total & 52 & 38 & 67 & 24 & 181 \\
\hline
\end{tabular}

Table 2. Correction of thoracic and thoracolumbar and lumbar TB treated by anterior or posterior instrumentation

\begin{tabular}{llll}
\hline & Anterior group & Posterior group & p value \\
\hline Patients, n & 74 & 83 & - \\
Infected vertebrae & $2.89 \pm 0.68$ & $2.95 \pm 0.71$ & $>0.05$ \\
Fusion level $^{\text {Average kyphosis angle, }}{ }^{\circ}$ (preop/postop) & $4.11 \pm 0.67$ & $4.21 \pm 1.06$ & $>0.05$ \\
Averaged angle of correction, $^{\circ}$ & $22.1 / 10.6^{\mathrm{a}}$ & $7.4 /-6.2^{\mathrm{a}}$ & $<0.01 /<0.01$ \\
Averaged angle loss of correction, $^{\circ}$ & $11.5 \pm 2.7$ & $12.6 \pm 1.2$ & $<0.01$ \\
& $6.8 \pm 1.9^{\mathrm{b}}$ & $6.1 \pm 1.3^{\mathrm{b}}$ & $<0.01$ \\
\hline
\end{tabular}

a There were statistically significant differences between the preoperative and postoperative average kyphosis angle (Student's t test, $\mathrm{p}<0.01$ ).

$\mathrm{b}$ There were statistically significant differences between the postoperative average kyphosis angle and that at the last follow-up (Student's t test, $\mathrm{p}<0.01$ ).

The standard four-drug therapy of isoniazid ( $5 \mathrm{mg} / \mathrm{kg})$, rifampicin $(10 \mathrm{mg} / \mathrm{kg})$, ethambutol $(15 \mathrm{mg} / \mathrm{kg})$ and pyrazinamide $(25$ $\mathrm{mg} / \mathrm{kg}$ ) was administered postoperatively as a first-line treatment and continued for a total of 3 months, followed by three-drug antituberculous treatment (rifampicin/isoniazid/ethambutol) for at least 9 months. Student's t test was used to analyze the statistical significance among anterior and posterior instrumentation groups. A value of $\mathrm{p}<0.05$ was considered to be statistically significant.

\section{Results}

One hundred and eighty-one patients were followed up for an average of 37 months ( $37 \pm 6.9$ months). The distribution of pathologic vertebrae in each group is shown in table 1. Maximal average operation time and blood loss occurred in group $B$, followed by group $A$; the minimum occurred in groups $C$ and $D$. Local symptoms of all patients were relieved significantly $(\mathrm{p}<0.01) 1-3$ weeks postoperatively. There was also a significant de- crease $(\mathrm{p}<0.05)$ in mean preoperative $(81 \%)$ Oswestry's Disability Index. Erythrocyte sedimentation rates returned to normal 8-12 weeks postoperatively. Fusion rates of the bone graft were $68(92.5 \%)$ cases in group A, $64(91.6 \%)$ cases in group B, 9 (92.1\%) cases in group C and $25(91.3 \%)$ cases in group D at the final follow-up. Except patients with lumbosacral TB who were only instrumented posteriorly, kyphosis degrees of the patients with thoracic and thoracolumbar and lumbar TB were corrected by a mean of $11.5^{\circ}$ in the anterior instrumentation group and $12.6^{\circ}$ in the posterior instrumentation group ( $\mathrm{p}<0.01$ ), whereas the correction loss was $6.8^{\circ}$ in the anterior instrumentation group and $6.1^{\circ}$ in the posterior instrumentation group at the last follow-up ( $\mathrm{p}<$ 0.01 ; table 2). Of the 25 cases with neurological deficit, 14 patients with grade $\mathrm{D}$ recovered to completely normal, 7 patients with grade $\mathrm{C}$ also recovered completely, and the other 4 improved to grade D. No patients deteriorated, including those with no neurological deficit preoperatively. Three sinuses were found in groups A, B 
and C $0.5,1$ and 1.5 months postoperatively, respectively, which were cured by change of dressing after 1-2 months. Instrumentation loosening was found in $1 \mathrm{pa}-$ tient in group A at 1-year follow-up. The patient was asymptomatic and the strut graft had fused at that time. Ten (5.5\%) cases had major drug complications, 7 had abnormal liver function, 4 combined with gastrointestinal tract reaction, 3 with abnormal renal function. After replacing rifampicin with rifapentine (twice a week), the patients recovered gradually. Severe complications did not occur.

\section{Discussion}

Spinal TB is traditionally treated surgically by anterior instrumented fusion [9], combined anterior-posterior procedure [10], extrapleural anterolateral procedure or posterior procedure only [11]. However, in this study posterior instrumentation was superior to anterior instrumentation in correcting the kyphosis deformity of the thoracic and lumbar spine and in maintaining that correction. The probable reason for this might be that pedicle screws cross the vertebral body pedicle, the strongest part of the vertebral body, providing three-dimensional correction and strengthening the spinal three-column stability, which is much stronger than anterior instrumentation. For patients with two or more segments of spinal TB, more than two pairs of pedicle screws were often used to avoid instability, and were removed after fusion without leading to excessive loss of movement of the spine. Anterior instrumentation, consisting of four screws fixed in the vertebral body and used only in the cephalic and caudal vertebrae adjacent to the lesion, could not provide the same strength as pedicle screws. Although anterior instrumentation is used more often in the thoracic region, which has support from the bony thorax, the screw cannot yet provide the same strength as the pedicle screw, which could lead to osteoporosis of the vertebral body caused by spinal TB.

Our finding that the posterior approach was superior to anterior instrumentation confirmed previous studies [12-14] where remarkable correction of the kyphotic deformity was achieved, and loss of correction after surgery was negligible. Güven et al. [12] reported a series of 10 cases with posterior instrumentation, in which there was a $3.4^{\circ}$ loss in the correction of local kyphosis. Moon et al. [13] and Chen et al. [14] reported 44 and 29 patients with spinal TB, respectively, who were treated by anterior radical surgery combined with posterior instrumentation and fusion. They achieved remarkable correction of the kyphotic deformity, and loss of correction after surgery was negligible $\left(1-3^{\circ}\right)$. However, other studies $[5,9]$ showed that anterior instrumentation increased the rate of correction of the kyphotic deformity and was effective in maintaining it. Benli et al. [9] observed that anterior instrumentation increased the rate of correction of the kyphotic deformity $(79.7 \pm 20.1 \%)$ and was effective in maintaining it, with an average loss of $1.1 \pm 1.7^{\circ}$. In the report of Jin et al. [5], a mean of $18^{\circ}$ of kyphosis correction was achieved after anterior instrumentation surgery in the adult group during the follow-up period. In contrast, Kim et al. [15], who operated on 21 patients with Pott disease by anterior instrumentation, mentioned that although a $67.7 \%$ correction $\left(11.3^{\circ}\right)$ was achieved initially, a correction of $83 \%\left(9.4^{\circ}\right)$ was lost at the latest followup. Lee et al. [16] reported that the correction of the kyphotic angle and loss of correction were statistically significant $(\mathrm{p}<0.05)$ in both the anterior instrumentation and fusion groups and the single-stage transpedicular decompression and the posterior instrumentation groups. The correction loss in the anterior instrumentation group of our series was $6.8 \pm 1.9^{\circ}$, comparable to the $9.4^{\circ}$ loss in the series of Kim et al. [15]. Similarly, the correction loss in the posterior instrumentation group in the present study was $6.1 \pm 1.3^{\circ}$, comparable to the $3.4^{\circ}$ loss in the series of Güven et al. [12]. There are statistically significant differences between the postoperative average kyphosis angle and that at the last follow-up in our series, similar to the series of Lee et al. [16]. The difference between our study and that by Moon et al. [13] might be that the number of subjects in their study is small. The difference between our study and Benli et al. [9] may be that the conditions of our patients was more serious than theirs, and the small number of their patients might be another reason.

\section{Conclusion}

Good outcomes were obtained with all the surgical procedures performed in correction of the deformity and maintaining correction, clearance of the foci, decompression of the spinal cord and pain relief in the treatment of spinal TB in adults providing that the operative indication is accurately identified, although posterior instrumentation was superior to anterior instrumentation for correcting deformity and maintaining that correction. 


\section{References}

-1 Talu U, Gogus A, Ozturk C, et al: The role of posterior instrumentation and fusion after anterior radical debridement and fusion in the surgical treatment of spinal tuberculosis: experience of 127 cases. J Spinal Disord Tech 2006; 19:554-559.

2 Jain AK: Tuberculosis of the spine: a fresh look at an old disease. J Bone Joint Surg Br 2010;92:905-913.

-3 Abuaku BK, Tan H, Chen M, et al: A comparative analysis of tuberculosis treatment success between Hunan Province of China and Eastern Ghana. Med Princ Pract 2010;19: 451-456.

4 Nagashima H, Yamane K, Nishi T, et al: Recent trends in spinal infections: retrospective analysis of patients treated during the past 50 years. Int Orthop 2010;34:395-399.

$>5$ Jin D, Qu D, Chen J, et al: One-stage anterior interbody autografting and instrumentation in primary surgical management of thoracolumbar spinal tuberculosis. Eur Spine J 2004; 13:114-121.
Swanson AN, Pappou IP, Cammisa FP, et al: Chronic infections of the spine: surgical indications and treatments. Clin Orthop Relat Res 2006;444:100-106.

7 Huang QS, Zheng C, Hu Y, et al: One-stage surgical management for children with spinal tuberculosis by anterior decompression and posterior instrumentation. Int Orthop 2009; 33:1385-1390.

8 Zaveri GR, Mehta SS: Surgical treatment of lumbar tuberculous spondylodiscitis by transforaminal lumbar interbody fusion (TLIF) and posterior instrumentation. J Spinal Disord Tech 2009;22:257-262.

$\checkmark 9$ Benli IT, Acaroglu E, Akalin S, et al: Anterior radical debridement and anterior instrumentation in tuberculosis spondylitis. Eur Spine J 2003; 12:224-234.

10 Sundarajan GD, Behera S, Ravi V, et al: The role of posterior stabilisation in the management of tuberculosis of the dorsal and lumbar spine. J Bone Joint Surg Br 2003;85:100-106.

11 Bezer M, Kucukdurmaz F: Transpedicular decancellation osteotomy in the treatment of posttuberculous kyphosis. J Spinal Disord Tech 2007;20:209-215.
2 Güven O, Kumano K, Yalcin S, et al: A single stage posterior approach and rigid fixation for preventing kyphosis in the treatment of spinal tuberculosis. Spine 1994;19:1039-1043.

13 Moon MS, Woo YK, Lee KS, et al: Posterior instrumentation and anterior interbody fusion for tuberculous kyphosis of dorsal and lumbar spines. Spine 1995;20:1910-1916.

$\checkmark 14$ Chen WJ, Wu CC, Jung CH, et al: Combined anterior and posterior surgeries in the treatment of spinal tuberculous spondylitis. Clin Orthop Relat Res 2002;398:50-59.

15 Kim KS, Ko SH, Youm KS: Anterior spinal instrumentation in treatment of spinal tuberculosis. J Kor Orthop Assoc 1998;33:15601568.

16 Lee SH, Sung JK, Park YM: Single-stage transpedicular decompression and posterior instrumentation in treatment of thoracic and thoracolumbar spinal tuberculosis: a retrospective case series. J Spinal Disord Tech 2006;19:595-602. 